\title{
A Cross-Sectional Epidemiological Survey of Work-Related Musculoskeletal Disorders and Analysis of Its Influencing Factors among Coal Mine Workers in Xinjiang
}

\author{
Xianting Yong, Fuye Li, Hua Ge, Xuemei Sun, Xiaofan Ma, and Jiwen Liu \\ Department of Occupational Health and Environmental Health, College of Public Health, Xinjiang Medical University, \\ Urumqi, China
}

Correspondence should be addressed to Jiwen Liu; liujiwendr@sina.com

Received 13 February 2020; Revised 15 July 2020; Accepted 31 July 2020; Published 10 August 2020

Academic Editor: José L. Campos

Copyright (c) 2020 Xianting Yong et al. This is an open access article distributed under the Creative Commons Attribution License, which permits unrestricted use, distribution, and reproduction in any medium, provided the original work is properly cited.

\begin{abstract}
This study is to investigate the prevalence of work-related musculoskeletal disorders (MSDs) and the influencing factors among coal mine workers employed in on-site operations. The job burnout scale and MSD scale were implemented to investigate a random sample of 1,500 coal mine workers working in on-site operations in Xinjiang, China. In total, 1,325 valid questionnaires were collected, with a recovery rate of $88.33 \%(1,325 / 1,500)$. The rate of job burnout was $90 \%$, of which $39.8 \%$ were categorized as mild burnout, $43.8 \%$ as moderate burnout, and $6.4 \%$ as severe burnout; the average job burnout score was $50.77 \pm 11.93$. The annual prevalence of MSDs was $65.6 \%$, with the highest annual prevalence in the waist (50.7\%), followed by the neck, shoulder, and knee, and the lowest prevalence in the elbow (18.8\%). Of the areas of the body affected by work-related MSDs, the highest proportion of requests for leave of absence was related to the waist, accounting for $25.7 \%$ of requests, while the lowest proportion (13.4\%) was related to the wrist. In addition, the incidence of MSDs increased with the years of service. The lowest incidence of MSDs was associated with the two-shift and three-group working pattern. The prevalence of MSDs in the neck and waist was higher in women than in men. The prevalence of MSDs in various body parts increased with the years of service. Moreover, multiple logistic regression indicated that three shifts with four groups (OR $=1.096,95 \%$ CI: 0.832-1.445), working more than 10 years $(\mathrm{OR}=3.396,95 \% \mathrm{CI}: 2.369-5.748)$, working more than 20 years $(\mathrm{OR}=3.008,95 \%$ CI: 1.419-6.337), significant bending ( $\mathrm{OR}=2.062$, 95\% CI: 1.400-3.038), forward neck tilting ( $\mathrm{OR}=1.572$, 95\% CI: 1.071-2.281), maximum force operation within a short period of time $(\mathrm{OR}=1.7222,95 \% \mathrm{CI}: 1.164-2.547)$, repeated movement of upper arms or fingers $(\mathrm{OR}=1.495,95 \%$ CI: 1.034-2.161), slip or fall incidents $(\mathrm{OR}=1.124,95 \% \mathrm{CI}: 1.039-1.216)$, work under conditions of cold or temperature variations $(\mathrm{OR}=1.911,95 \% \mathrm{CI}: 1.342-2.720)$, mild burnout ( $\mathrm{OR}=1.492,95 \% \mathrm{CI}: 1.016-2.191)$, moderate burnout $(\mathrm{OR}=1.852,95 \% \mathrm{CI}: 1.267-2.708)$, and severe burnout $(\mathrm{OR}=2.001,95 \% \mathrm{CI}: 1.145-3.496)$ were risk factors for MSDs. In conclusion, there is a high annual prevalence of MSDs among the coal mine workers employed in on-site operations in Xinjiang, China. Measures to reduce this prevalence are required.
\end{abstract}

\section{Introduction}

Work-related musculoskeletal disorders (MSDs) refer to an injury or dysfunction of muscles, bones, nerves, tendons, ligaments, joints, cartilage, and spine [1]. It has been reported that $30 \%$ of European workers suffer from back pain, and the economic loss caused by back pain in Holland accounts for $1.7 \%$ of the national wealth every year. Furthermore [2, $3]$, the number of days absent from work due to MSDs accounts for $15 \%-22 \%$ of the total as a consequence of industry-related diseases in the Federal Republic of Germany every year. The direct and indirect economic losses incurred in Canada due to MSDs are as high as nearly 100 billion US dollars every year. Thus, the serious consequences of MSDs have gradually aroused widespread concern in economically developed countries [4]. Indeed, MSDs can also be induced by adverse psychosocial factors, which in turn have negative effects on psychological and social states and further increase the risk of workers, thus exhibiting a two-way connection and feedback loop between the two [5-7]. Under cognitive 
and emotional stress, a longer period of rest time is required to allow muscle relaxation [8]. Although coal mine workers are high-risk groups for MSDs [9-11], the influence of psychosocial factors in this group remains to be clarified. There is a wide range of psychosocial factors, including job demands, job control, job support, social support, and job satisfaction [12]. Furthermore, some studies have shown that, especially in developing countries, individual physical, social, and organizational risk factors are independent predictors of lumbar back symptoms (LBS), although on their interactions have seldom been explored. Previous studies have shown that psychosocial factors are more likely to lead to LBS than physical factors, among which the night shift and unreasonable shift systems are also risk factors [13, 14]. Additionally, a study in Indonesian coal miners showed interactions between lumbago symptoms and physical and psychological risk factors, with a higher incidence of lumbago symptoms among smokers and permanent night shift workers although the mechanisms remain to be clarified [15].

MSDs are a serious threat to health, working ability, and quality life and represent the primary reason for the decline in the working population aged from 20 to 55. In some industrialized countries, traditional occupational diseases caused by chemical toxicity, dust, and noise have been gradually controlled, while chronic MSDs of the waist, back, shoulder, neck, and wrist have become widespread occupational health problems associated with high economic losses [16]. Thus, the psychology and musculoskeletal health of coal mine workers in specialized environments require further investigation.

In China, the coal mine workers are in a large population alling into the category of specialized occupations as a consequence of the rich coal resources. Specifically, coal miners are engaged in long-term operations executed hundreds, or even thousands, of meters underground, where the working environment is complicated, with a high level of responsibility and long working hours, resulting in an unstable biological rhythm. In addition, the working environment contains occupational risk factors such as high temperature, noise, dust, vibration, and unreasonable working systems, which have adverse effects on the psychology of coal miners [17]. In this study, using a questionnaire survey, we investigated the prevalence of MSDs and related influencing factors among coal miners working in an on-site operation in Xinjiang. This information will provide a scientific reference for further improving the quality of life of coal miners and establishing a healthy and harmonious working environment.

\section{Methods}

2.1. Participants. This cross-sectional study was conducted via questionnaire using random cluster sampling. From March 2017 to December 2017, 1,500 coal mine workers employed in on-site operations at six coal mine enterprises in Xinjiang were randomly selected for inclusion in our study. The participants were aged 18 years or over and under 60 years with $\geq 1$ year of service. A total of 1,500 questionnaires were distributed in this survey. After the exclusion of the invalid questionnaires, 1,325 valid questionnaires were finally returned, with a recovery rate of $88.33 \%$.

2.2. Job Burnout. In this study, we used the job burnout scale revised by Li et al. [18] to measure job burnout. The questionnaire was designed to evaluate emotional exhaustion, depersonalization, and reduced sense of achievement, with five items included for each factor (15 items in total). The Cronbach $\alpha$ coefficient of the questionnaire was 0.780 and the test-retest reliability was 0.843 [19]. Based on a previous report, these values indicate that the reliability and validity of the questionnaire are good and that the questionnaire is eligible for psychological evaluations [20]. There were four job burnout sublevels: zero burnout (emotional exhaustion $<25$, depersonalization $<11$, and reduced sense of achievement $<16$ ), mild burnout (emotional exhaustion $\geq 25$, depersonalization $<11$, and reduced sense of achievement $<16$; emotional exhaustion $<$ 25 , depersonalization $\geq 11$, and reduced sense of achievement $<16$; or emotional exhaustion $<25$, depersonalization $<11$, and reduced sense of achievement $\geq 16$ ), moderate burnout (emotional exhaustion $\geq 25$, depersonalization $\geq 11$, and reduced sense of achievement $<16$; emotional exhaustion $\geq$ 25 , depersonalization $<11$, and reduced sense of achievement $\geq 16$; or emotional exhaustion $<25$, depersonalization $\geq 11$, and reduced sense of achievement $\geq 16$ ), and severe burnout (emotional exhaustion $\geq 25$, depersonalization $\geq 11$, and reduced sense of achievement $\geq 16$ ). The critical values of the three levels of the job burnout scale were defined as $\geq 25$, $\geq 11$, and $\geq 16$.

2.3. MSDs. The MSD questionnaire jointly developed by Kapitan et al. was adopted in this study $[21,22]$. The questionnaire, which has good reliability and validity, includes general conditions (17 items), health conditions (three sections evaluating work-related pain or discomfort in nine areas of the body (neck, shoulder, back, elbow, waist, wrist, hip, knee, and, ankle, and foot) in the past year and in the past week), and working conditions. The working conditions included movements requiring great effort (such as lifting, pushing, pulling, unfavorable posture, and trunk bending), dynamic loads (trunk movements and neck, shoulder, and wrist movements, etc.), static loads (including slight bending and severe bending), repetitive loads (i.e., work with the same movement), ergonomic environment (working environment, lack of support, slipping and falling, forward movement with tools, etc.), and environmental temperature. Most questions required a simple "yes" or "no" answer.

2.4. Quality Control. Quality control was monitored throughout the on-site investigations and study, including at the design stage (questionnaire design, investigators, on-site investigation, and data collation).

2.5. Statistical Analysis. All data were entered into the EpiData 3.0 database and analyzed using the SPSS 20.0 software package. All measurement data were reported as the mean \pm standard deviation (SD). Two independent-sample $t$-tests were used to evaluate differences between two groups, whereas differences among several groups were evaluated by one-way analysis of variance (ANOVA). If an overall 
difference was found, Student-Newman-Keuls- (SNK-) $q$ tests were used for multiple comparisons. Comparison of rates was performed using chi-squared tests. A multivariate logistic regression model of MSDs of coal mine workers was established by incorporating variables with $P<0.1$ in univariate analysis into the logistic regression equation. Furthermore, the analysis of factors affecting job burnout and MSDs was conducted through univariate and multivariate logistic regression models. The test level was $\alpha=0.05$.

\section{Results}

3.1. Baseline Data. The baseline data for the participants are shown in Table 1 . A total of 1,500 questionnaires were distributed and 1,325 valid questionnaires were returned, with a recovery rate of $88.3 \%$. Specifically, the respondents comprised 1,220 men and 105 women, with a mean age of 42.2 \pm 8.7 years and a mean length of service of $17.5 \pm 10.6$ years. Regarding education background, $43.8 \%$ of participants had received a junior high school education or lower, $31.5 \%$ had received a senior high school or technical secondary school education, $18.4 \%$ had received a junior college education, and $6.2 \%$ had a bachelor's degree or higher.

3.2. Investigation on Job Burnout among Coal Miners. In terms of job burnout among the coal mine workers, we recorded a mean score of $50.77 \pm 11.93$, with job burnout detected in $90.0 \%$ of participants. The emotional exhaustion score was $16.83 \pm 7.77$, the depersonalization score was $12.61 \pm 6.90$, and the reduced sense of achievement score was $21.35 \pm 7.66$. In terms of the degree of job burnout among the coal mine workers, 527 (39.8\%) were classified as slight burnout, 581 (43.8\%) were classified as moderate burnout, and 85 (6.4\%) were classified as severe burnout.

3.3. Weekly Prevalence of MSDs among Coal Miners. The weekly prevalence of MSDs among coal mine workers is shown in Table 2. The highest weekly prevalence of MSDs among the coal mine workers was related to the waist $(41.3 \%)$, followed by the neck (32.2\%), shoulder $(27.4 \%)$, elbow (14.4\%), and ankle (14.4\%). The highest rate of MSDs resulting in a request for leave of absence was related to the waist $(14.8 \%)$, while the lowest rate was related to the wrist (9.4\%).

3.4. Annual Prevalence of MSDs among Coal Mine Workers. The annual prevalence of MSDs among coal mine workers is shown in Table 3 . The annual prevalence of MSDs among coal mine workers was $65.6 \%$, which was dominated by MSDs related to the waist, neck, and shoulder and knee (juxtaposed). The highest annual prevalence of MSDs was related to the waist (50.7\%), while the lowest was related to the elbow (18.8\%). The highest rate of MSDs causing requests for leave of absence was related to the waist $(25.7 \%)$, while the lowest rate was related to the wrist (13.4\%).

3.5. Univariate Logistic Regression Model of MSDs of Coal Mine Workers. Details of the factors influencing MSD prevalence are shown in Table 4. The significant influencing factors identified for MSDs among coal mine workers were as follows: years of service, significant bending, forward neck tilting, maximum force operation over a period of time, repeated movements of the upper arms or fingers, slip or fall incidents, work under conditions of cold or temperature variations, and job burnout levels. The prevalence of MSDs among coal mine workers increased with the years of services. In terms of the shift system, the lowest incidence of MSDs was associated with the two-shift with three-group pattern. Job burnout was identified as a risk factor for MSDs, with severe job burnout associated with a significantly higher risk of illness compared with that of the no burnout group $(P<0.05)$.

3.6. Multivariate Logistic Regression Model of MSDs of Coal Mine Workers. The results of the multivariate logistic regression analysis of MSDs among coal mine workers are shown in Table 5. Significant bending, forward neck tilting, maximum force operation within a short period of time, repeated movements of the upper arms or fingers, slip or fall incidents, and work under conditions of cold or temperature variations had positive contributions to the prevalence of MSDs among coal mine workers $(P<0.05)$. Burnout increases the risk of musculoskeletal injuries. By comparing the coal miners without burnout, mild burnout, moderate burnout, and severe burnout, we found that with the increase of occupational burnout, the prevalence of musculoskeletal diseases of coal mine workers also increased. These results indicate that the higher the degree of job burnout, the greater the risk of illness.

\section{Discussion}

Coal mine workers represent a huge population in China's workforce (nearly 100,000 are employed in Xinjiang), requiring special attention regarding their physical and mental health. Many risk factors for MSDs are associated with the daily activities of coal mine workers, including the physical stress caused by dynamic and static loads, as well as ergonomic and environmental factors. The prevalence of MSDs in the general working population ranges from $20 \%$ to $40 \%$ [23-26]. Our survey showed that the annual prevalence of MSDs among coal mine workers on site is $65.6 \%$, which is higher than that of the general working population and lower than that $(78.4 \%)$ reported in 2011 by $\mathrm{Xu}$ [27]. As previously reported [28, 29], the prevalence of MSDs for gas station employees is $51.2 \%$ and that for nursing staff is $78.58 \%$. The top three positions in terms of the prevalence of MSDs for nursing staff [29], automobile manufactory workers [30], oil extraction workers [31], and power plant workers [32] are the waist, neck, and shoulder, which is consistent with the results obtained in this study. The waist is an important region for normal movement of the human body. The five postures of standing, lifting, squatting, sitting, and carrying all out strain on the waist, which are inevitable aspects of all types of work, thus having a greater impact on the work once the waist has been injured. Therefore, the waist is ranked first among the positions leading to absence due to illness, followed by the ankle, possibly due the pressure imposed on this joint by the long distances traveled by coal 
TABLe 1: Baseline data.

\begin{tabular}{|c|c|c|c|}
\hline Variables & & $n$ & $\%$ \\
\hline \multirow{2}{*}{ Gender } & Male & 1,220 & 92.1 \\
\hline & Female & 105 & 7.9 \\
\hline \multirow{4}{*}{ Age (years) } & $<30$ & 171 & 12.9 \\
\hline & $30+$ & 254 & 19.2 \\
\hline & $40+$ & 609 & 46 \\
\hline & $50+$ & 291 & 22 \\
\hline \multirow{3}{*}{ Years of service } & $<10$ & 402 & 30.3 \\
\hline & $10+$ & 305 & 23 \\
\hline & $20+$ & 618 & 46.6 \\
\hline \multirow{3}{*}{ Education } & Junior high school or lower & 581 & 43.8 \\
\hline & Senior high school or technical secondary & 418 & 31.5 \\
\hline & Junior college & 244 & 18.4 \\
\hline \multirow{20}{*}{ Type of work } & Bachelor's degree or higher & 82 & 6.2 \\
\hline & Coal miner & 231 & 17.4 \\
\hline & Coal caver & 26 & 2 \\
\hline & Coal drivage worker & 238 & 18 \\
\hline & Anchor worker & 11 & 0.8 \\
\hline & Craft worker & 26 & 2 \\
\hline & Inspection worker & 31 & 2.3 \\
\hline & Ventilation worker & 48 & 3.6 \\
\hline & Gangue collector & 21 & 1.6 \\
\hline & Electric locomotive driver & 26 & 2 \\
\hline & Bell man & 38 & 2.9 \\
\hline & Electrical fitter & 158 & 11.9 \\
\hline & Plugman & 18 & 1.4 \\
\hline & Operator & 42 & 3.2 \\
\hline & Blaster & 20 & 1.5 \\
\hline & Gas inspector & 27 & 2 \\
\hline & Backman & 49 & 3.7 \\
\hline & Monitor observer & 22 & 1.7 \\
\hline & Loading workman & 25 & 1.9 \\
\hline & Others & 266 & 20.1 \\
\hline \multirow{4}{*}{ Shift system } & Day shift only & 490 & 37 \\
\hline & Two shifts & 187 & 14.1 \\
\hline & Two shifts with three groups & 536 & 40.5 \\
\hline & Three shifts with four groups & 112 & 8.5 \\
\hline \multirow{3}{*}{ Marital status } & Unmarried & 126 & 9.5 \\
\hline & Married & 1,156 & 87.2 \\
\hline & Divorced or widowed & 43 & 3.2 \\
\hline
\end{tabular}

mine workers from their homes to the mine and the requirement to remain standing for long periods of time during their working hours.

In terms of demographic factors, a previous study revealed a higher prevalence of MSDs related to the waist and neck in women than in men [31]. The prevalence of MSDs in the hip and knee also increased with the age of the participants, with the highest prevalence rate in the waist in individuals aged between 40 and 50 years. In con- trast, there were no significant differences in the prevalence of MSDs at other positions. Our results showed that the prevalence of MSDs increased with the number of years of services, which is consistent with previous studies [33-35] especially after the 10 or more years of services. This phenomenon results in a more rapid increase in the prevalence of MSDs in this group than that of workers with less than 10 years of service, in contrast to slowed increase in the prevalence of MSDs when the years 
TABLE 2: Weekly prevalence of MSDs among coal mine workers.

\begin{tabular}{|c|c|c|c|c|c|}
\hline \multirow{2}{*}{ Localizations } & \multirow{2}{*}{ Position } & \multicolumn{2}{|c|}{ MSD } & \multicolumn{2}{|c|}{ Leave of absence due to MSD } \\
\hline & & Number of patients & Weekly prevalence & Requests for leave of absence & Absence rate due to MSD \\
\hline \multirow{5}{*}{ Upper limb } & Neck & 427 & $32.20 \%$ & 43 & $10.10 \%$ \\
\hline & Shoulder & 363 & $27.40 \%$ & 37 & $10.20 \%$ \\
\hline & Back & 300 & $22.60 \%$ & 33 & $11.00 \%$ \\
\hline & Elbow & 191 & $14.40 \%$ & 25 & $13.10 \%$ \\
\hline & Wrist & 245 & $18.50 \%$ & 23 & $9.40 \%$ \\
\hline \multirow{4}{*}{ Lower limb } & Waist & 547 & $41.30 \%$ & 81 & $14.80 \%$ \\
\hline & Hip & 146 & $11.00 \%$ & 19 & $13.00 \%$ \\
\hline & Knee & 328 & $24.80 \%$ & 39 & $11.90 \%$ \\
\hline & Ankle & 191 & $14.40 \%$ & 28 & $14.70 \%$ \\
\hline
\end{tabular}

TABLE 3: Annual prevalence of MSDs among coal mine workers.

\begin{tabular}{lccccc}
\hline \multirow{2}{*}{ Localizations } & \multirow{2}{*}{ Position } & \multicolumn{2}{c}{ Illness } & \multicolumn{2}{c}{ Request for leave of absence due to illness } \\
Absence rate due to illness
\end{tabular}

of service exceed 20. In general, coal mine workers, who are mainly engaged in manual labor, are prone to sickness caused by overwork under the influence of various adverse factors. However, with the experience that comes with increasing years of services, these workers learn strategies to avoid adverse working postures. On the other hand, under the influence of their own MSDs, the working efficiency of these individuals decreases and they cannot maintain their previous workload. As a result, the prevalence of MSDs increases less in the groups with 10 to 20 years of service and those with more than 20 years of service. The univariate logistic regression analysis of the groups classified according to years of services revealed that the risk of MSDs in the groups with more than 20 years and between 10 and 20 years of service was higher than that of the group with less than 10 years of services, respectively. These results confirm that the increase in the number of years of services is a risk factor for MSDs in coal mine workers. Furthermore, the results also show that the prevalence of MSDs among coal mine workers is the lowest in those employed under the system of two shifts with three groups. This employment practice was also shown to be protective against MSDs compared with that of individuals working day shifts only. The comprehensive evaluation based on the establishment of a logistic regression model revealed the existence of numerous influencing factors for MSDs among coal mine workers including significant bending, forward neck tilting, maximum force operation within a short period of time, and repeated movements of upper arms or fingers, all of which are inevitable and occur frequently in the labor process [36]. In addition, low temperature and humidity in the coal mine also have substantial influences on the work, as causes of slip and fall incidents and showing an association with environmental changes [7].

The prevalence of MSDs in various positions of coal miners with severe burnout is much higher than that of coal miners affected by job burnout to a lesser degree, suggesting that there is a certain relationship between job burnout and MSDs in this population and confirming that job burnout is a risk factor for MSDs. Psychosocial factors have been reported to have a noticeable effect on MSDs [37, 38], with adverse psychosocial factors shown to change human behavior and lead to the occurrence of MSDs [39] via a two-way feedback between psychosocial factors and MSDs [40]. Studies outside China have also shown that psychological factors and physical load simultaneously influence the prevalence of MSDs [41].

This study focused on the coal mine workers on site in Xinjiang; therefore, further studies are required to determine and verify our results in other regions. In addition, we investigated the prevalence of MSDs without clarification of the 
TABLE 4: Factors influencing prevalence of MSD last year.

\begin{tabular}{|c|c|c|c|c|c|c|}
\hline \multirow[b]{2}{*}{ Variables } & & \multirow{2}{*}{$\begin{array}{l}\text { Prevalence of MSD } \\
\text { last year }\end{array}$} & \multirow[b]{2}{*}{$P$} & \multirow[b]{2}{*}{ OR } & \multicolumn{2}{|c|}{$95 \% \mathrm{CI}$} \\
\hline & & & & & $\begin{array}{l}\text { Upper } \\
\text { limit }\end{array}$ & $\begin{array}{c}\text { Lower } \\
\text { limit }\end{array}$ \\
\hline \multirow[t]{3}{*}{ Gender } & & & 0.273 & & & \\
\hline & Male & $65.20 \%$ & & 1 & & \\
\hline & Female & $70.00 \%$ & & 1.276 & 0.826 & 1.973 \\
\hline \multirow[t]{5}{*}{ Age (years) } & & & 0.097 & & & \\
\hline & $<30$ & $59.60 \%$ & & 1 & & \\
\hline & $30+$ & $63.00 \%$ & & 1.151 & 0.774 & 1.714 \\
\hline & $40+$ & $68.80 \%$ & & 1.492 & 1.051 & 2.118 \\
\hline & $50+$ & $64.60 \%$ & & 1.235 & 0.837 & 1.821 \\
\hline \multirow[t]{4}{*}{ Years of service } & & & 0.001 & & & \\
\hline & $<10$ & $58.50 \%$ & & 1 & & \\
\hline & $10+$ & $67.20 \%$ & & $1.457^{*}$ & 1.068 & $1.988^{*}$ \\
\hline & $20+$ & $69.40 \%$ & & $1.613^{* *}$ & 1.241 & 2.096 \\
\hline \multirow[t]{5}{*}{ Education } & & & 0.689 & & & \\
\hline & Junior high school or lower & $63.90 \%$ & & 1 & & \\
\hline & $\begin{array}{l}\text { Senior high school or technical } \\
\text { secondary }\end{array}$ & $67.00 \%$ & & 1.148 & 0.881 & 1.497 \\
\hline & Junior college & $66.40 \%$ & & 1.118 & 0.816 & 1.532 \\
\hline & Bachelor's degree or higher & $68.30 \%$ & & 1.219 & 0.743 & 2.000 \\
\hline \multirow[t]{5}{*}{ Shift system } & & & 0.002 & & & \\
\hline & Day shift only & $67.30 \%$ & & 1 & & \\
\hline & Two shifts & $71.70 \%$ & & 1.226 & 0.847 & 1.774 \\
\hline & Two shifts with three groups & $60.10 \%$ & & $0.730^{*}$ & 0.565 & 0.942 \\
\hline & Three shifts with four groups & $74.10 \%$ & & 1.338 & 0.873 & 2.205 \\
\hline \multirow[t]{3}{*}{ Significant bending } & & & $<0.001$ & & & \\
\hline & No & $54.10 \%$ & & 1 & & \\
\hline & Yes & $75.10 \%$ & & $2.723^{* *}$ & 2.141 & 3.462 \\
\hline \multirow[t]{3}{*}{ Forward neck tilting } & & & $<0.001$ & & & \\
\hline & No & $53.10 \%$ & & 1 & & \\
\hline & Yes & $76.80 \%$ & & $2.967^{* *}$ & 2.337 & 3.767 \\
\hline \multirow[t]{3}{*}{$\begin{array}{l}\text { Maximum force operation within a short } \\
\text { period of time }\end{array}$} & & & $<0.001$ & & & \\
\hline & No & $55.00 \%$ & & 1 & & \\
\hline & Yes & $75.30 \%$ & & $2.655^{* *}$ & 2.088 & 3.376 \\
\hline \multirow[t]{3}{*}{$\begin{array}{l}\text { Repeated movement of upper arms or } \\
\text { fingers }\end{array}$} & & & $<0.001$ & & & \\
\hline & No & $56.80 \%$ & & 1 & & \\
\hline & Yes & $71.90 \%$ & & $1.941^{* *}$ & 1.538 & 2.450 \\
\hline \multirow[t]{3}{*}{ Slip or fall incidents } & & & $<0.001$ & & & \\
\hline & No & $55.00 \%$ & & 1 & & \\
\hline & Yes & $76.20 \%$ & & 2.744 & 2.155 & 3.495 \\
\hline \multirow[t]{3}{*}{$\begin{array}{l}\text { Work under conditions of cold or } \\
\text { temperature variations }\end{array}$} & & & $<0.001$ & & & \\
\hline & No & $52.00 \%$ & & 1 & & \\
\hline & Yes & $74.40 \%$ & & $2.688^{* *}$ & 2.121 & 3.405 \\
\hline \multirow[t]{2}{*}{ Burnout level } & & & 0.001 & & & \\
\hline & Zero burnout & $67.40 \%$ & & 1 & & \\
\hline
\end{tabular}


TABLE 4: Continued.

\begin{tabular}{|c|c|c|c|c|c|c|}
\hline \multirow[b]{2}{*}{ Variables } & & \multirow[b]{2}{*}{$\begin{array}{c}\text { Prevalence of MSD } \\
\text { last year }\end{array}$} & \multirow[b]{2}{*}{$P$} & \multirow[b]{2}{*}{ OR } & \multicolumn{2}{|c|}{ 95\% CI } \\
\hline & & & & & $\begin{array}{l}\text { Upper } \\
\text { limit }\end{array}$ & $\begin{array}{c}\text { Lower } \\
\text { limit }\end{array}$ \\
\hline & Mild burnout & $66.20 \%$ & & 0.904 & 0.599 & 1.365 \\
\hline & Moderate burnout & $61.80 \%$ & & 0.743 & 0.495 & 1.117 \\
\hline & Severe burnout & $84.70 \%$ & & 2.530 & 1.225 & 5.099 \\
\hline
\end{tabular}

Note: ${ }^{*} P<0.05 ;{ }^{* *} P<0.01$.

TABLE 5: Multivariate logistic regression analysis of prevalence of MSD last year of coal mine workers.

\begin{tabular}{|c|c|c|c|c|c|c|c|}
\hline \multirow{2}{*}{ Variables } & \multirow{2}{*}{ Variable assignment } & \multirow{2}{*}{$B$} & \multirow{2}{*}{ Wald } & \multirow{2}{*}{$P$} & \multirow{2}{*}{ OR } & \multicolumn{2}{|c|}{$95 \% \mathrm{CI}$} \\
\hline & & & & & & Upper limit & Lower limit \\
\hline \multirow{4}{*}{ Shift system } & Day shift only & & 25.635 & $<0.001$ & 1 & & \\
\hline & Two shifts & 0.092 & 0.427 & 0.514 & 1.096 & 0.832 & 1.445 \\
\hline & Two shifts with three groups & -0.437 & 3.294 & 0.070 & 0.646 & 0.403 & 1.306 \\
\hline & Three shifts with four groups & 0.811 & 17.294 & $<0.001$ & 2.271 & 1.543 & 3.342 \\
\hline \multirow{3}{*}{ Years of services } & $<10$ & & 31.662 & 0.01 & 1 & & \\
\hline & $10+$ & 1.306 & 33.332 & 0.000 & 3.690 & 2.369 & 5.748 \\
\hline & $20+$ & 1.101 & 8.251 & 0.004 & 3.008 & 1.419 & 6.377 \\
\hline \multicolumn{2}{|c|}{ Significant bending } & 0.724 & 13.395 & $<0.001$ & 2.062 & 1.400 & 3.038 \\
\hline \multicolumn{2}{|c|}{ Forward neck tilting } & 0.565 & 5.657 & 0.017 & 1.572 & 1.071 & 2.281 \\
\hline \multicolumn{2}{|c|}{ Maximum force operation within a short period of time } & 0.543 & 7.398 & 0.007 & 1.7222 & 1.164 & 2.547 \\
\hline \multicolumn{2}{|c|}{ Repeated movement of upper arms or fingers } & 0.402 & 4.575 & 0.032 & 1.495 & 1.034 & 2.161 \\
\hline \multicolumn{2}{|c|}{ Slip or fall incidents } & 0.117 & 8.475 & 0.004 & 1.124 & 1.039 & 1.216 \\
\hline \multicolumn{2}{|c|}{$\begin{array}{l}\text { Work under conditions of cold or temperature } \\
\text { variations }\end{array}$} & 0.647 & 12.915 & $<0.001$ & 1.911 & 1.342 & 2.720 \\
\hline \multirow{4}{*}{ Job burnout } & Zero burnout & & 11.462 & 0.009 & 1 & & \\
\hline & Mild burnout & 0.400 & 4.159 & 0.041 & 1.492 & 1.016 & 2.191 \\
\hline & Moderate burnout & 0.617 & 10.317 & 0.001 & 1.852 & 1.267 & 2.708 \\
\hline & Severe burnout & 0.694 & 5.935 & 0.015 & 2.001 & 1.145 & 3.496 \\
\hline
\end{tabular}

mechanism and etiology of MSDs in coal miners; thus, a cohort study is required to explore the causes and mechanisms of MSDs among coal miners.

\section{Conclusions}

In this cross-sectional study, we showed a high prevalence of MSDs among coal mine workers on site in Xinjiang. The prevalence of MSDs of the neck and waist was higher in women than in men. Furthermore, the prevalence of MSDs at each position increased with the years of service. In addition, the prevalence of MSDs in the neck of coal mine workers varied with educational background, while the prevalence in the wrist and knee varied with shift systems. Numerous factors influence the prevalence of MSDs among coal mine workers including shift system, years of services, significant bending, forward neck tilting, maximum force operation within a short period of time, repeated movements of upper arms or fingers, slip and fall incidents, work under conditions of cold or temperature variations, and job burnout, suggesting interventions to control these factors will be beneficial to both the body and mind of coal mine workers.

\section{Data Availability}

The data used to support the findings of this study are available from the corresponding author upon request.

\section{Ethical Approval}

The study was approved by the ethics committee of the Xinjiang Medical University (Approval No. 8176120048).

\section{Consent}

All participants provided written informed consent.

\section{Conflicts of Interest}

The authors declare that the research was conducted in the absence of any commercial or financial relationships that could be construed as a potential conflict of interest.

\section{Acknowledgments}

The study was supported by the National Natural Science Foundation of China [Grant No. 81760581], University 
Research Projects of Xinjiang Province [Grant No. XJEDU2019Y025], and Graduate Innovation and Entrepreneurship Program of Xinjiang Medical University [No. CXCY2018057].

\section{References}

[1] B. R. da Costa and E. R. Vieira, "Risk factors for work-related musculoskeletal disorders: a systematic review of recent longitudinal studies," American Journal of Industrial Medicine, vol. 53, no. 3, pp. 285-323, 2010.

[2] A. Mozafari, M. Vahedian, S. Mohebi, and M. Najafi, "Workrelated musculoskeletal disorders in truck drivers and official workers," Acta Medica Iranica, vol. 53, no. 7, pp. 432-438, 2015.

[3] E. Ö. Bulduk, "Work-related stress levels and musculoskeletal disorders among municipal solid waste collectors in Ankara," Work, vol. 63, no. 3, pp. 427-433, 2019.

[4] G. Boniface, S. Ghosh, and L. Robinson, "District nurses' experiences of musculoskeletal wellbeing: a qualitative study," British Journal of Community Nursing, vol. 21, no. 7, pp. 350-355, 2016.

[5] H. Costello, S. Walsh, C. Cooper, and G. Livingston, "A systematic review and meta-analysis of the prevalence and associations of stress and burnout among staff in long-term care facilities for people with dementia," International Psychogeriatrics, vol. 31, no. 8, pp. 1203-1216, 2019.

[6] T. M. de Araújo, T. M. Araújo, T. F. Palma, and N. D. C. Araújo, "Vigilância em saúde mental e trabalho no Brasil: características, dificuldades e desafios," Ciência \& Saúde Coletiva, vol. 22, no. 10, pp. 3235-3246, 2017.

[7] M. Deng, F. Wu, J. Wang, and L. Sun, "Musculoskeletal disorders, personality traits, psychological distress, and accident proneness of Chinese coal miners," Work, vol. 57, no. 3, pp. 441-449, 2017.

[8] A. K. Blangsted, K. Søgaard, H. Christensen, and G. Sjøgaard, "The effect of physical and psychosocial loads on the trapezius muscle activity during computer keying tasks and rest periods," European Journal of Applied Physiology, vol. 91, no. 2-3, pp. 253-258, 2004.

[9] C. P. Jiménez-Forero, I. T. Zabala, and Á. J. Idrovo, "Work conditions and morbidity among coal miners in Guacheta, Colombia: the miners' perspective," Biomédica, vol. 35, pp. 77-89, 2014.

[10] R. Tong, Y. Yang, X. Ma, Y. Zhang, S. Li, and H. Yang, "Risk assessment of miners' unsafe behaviors: a case study of gas explosion accidents in coal mine, China," International Journal of Environmental Research and Public Health, vol. 16, no. 10 , p. $1765,2019$.

[11] D. R. Smith, M. Mihashi, Y. Adachi, H. Koga, and T. Ishitake, "A detailed analysis of musculoskeletal disorder risk factors among Japanese nurses," Journal of Safety Research, vol. 37, no. 2, pp. 195-200, 2006.

[12] D. R. Smith, N. Wei, L. Zhao, and R. S. Wang, "Musculoskeletal complaints and psychosocial risk factors among Chinese hospital nurses," Occupational Medicine (London), vol. 54, no. 8, pp. 579-582, 2004.

[13] B. Widanarko, S. Legg, J. Devereux, and M. Stevenson, "Raising awareness of psychosocial factors in the occurrence of low back symptoms in developing countries," Work, vol. 41, pp. 5734-5736, 2012.
[14] R. Hanoa, V. Baste, A. Kooij, L. Sommervold, and B. E. Moen, "No difference in self reported health among coalminers in two different shift schedules at Spitsbergen, Norway, a two years follow-up," Industrial Health, vol. 49, no. 5, pp. 652-657, 2011.

[15] M. Gómez-Galán, J. Pérez-Alonso, Á. J. Callejón-Ferre, and J. López-Martínez, "Musculoskeletal disorders: OWAS review," Industrial Health, vol. 55, no. 4, pp. 314-337, 2017.

[16] P. Coenen, et al.G. N. Healy, E. A. H. Winkler et al., "Associations of office workers' objectively assessed occupational sitting, standing and stepping time with musculoskeletal symptoms," Ergonomics, vol. 61, no. 9, pp. 1187-1195, 2018.

[17] E. Wiernik, B. Pannier, S. Czernichow et al., "Occupational status moderates the association between current perceived stress and high blood pressure," Hypertension, vol. 61, no. 3, pp. 571-577, 2013.

[18] F. Li, H. Jiang, and J. Liu, "Analysis of reliability and validity of work locus of control scale," Journal of Xinjiang Medical University, vol. 31, no. 12, pp. 1655-1658, 2008.

[19] F. Li, J. Liu, Y. Lian, and Q. Wang, "Reliability and validity analysis of mental burner occupational burnout measurement tools," Chinese Journal of Occupational Health and Occupational Diseases, vol. 27, no. 3, pp. 156-159, 2009.

[20] Y. G. Choi, B. J. Choi, T. H. Park et al., "A study on the characteristics of Maslach burnout inventory-general survey (MBIGS) of workers in one electronics company," Annals of Occupational and Environmental Medicine, vol. 31, no. 1, article e29, 2019.

[21] M. Kapitán, N. Pilbauerová, L. Vavřičková, Z. Šustová, and S. Machač, "Prevalence of musculoskeletal disorders symptoms among Czech dental students. Part 1: a questionnaire survey," Acta Medica (Hradec Králové), vol. 61, no. 4, pp. 131-136, 2018.

[22] L. Yang, V. H. Hildebrandt, S. Yu et al., "Introduction of the questionnaire for musculoskeletal diseases with questionnaire," Industrial Health and Occupational Diseases, vol. 1, pp. 25-31, 2009.

[23] S. Warming, D. H. Precht, P. Suadicani, and N. E. Ebbehøj, "Musculoskeletal complaints among nurses related to patient handling tasks and psychosocial factors - based on logbook registrations," Applied Ergonomics, vol. 40, no. 4, pp. 569576, 2009.

[24] J. Kivimaki, H. Riihimaki, and K. Hanninen, "Knee disorders in carpet and floor layers and painters. Part II: knee symptoms and patellofemoral indices," Scandinavian Journal of Rehabilitation Medicine, vol. 26, no. 2, pp. 97-101, 1994.

[25] M. Agaliotis, M. G. Mackey, R. Heard, S. Jan, and M. Fransen, "Personal and workplace environmental factors associated with reduced worker productivity among older workers with chronic knee pain," Journal of Occupational and Environmental Medicine, vol. 59, no. 4, pp. e24-e34, 2017.

[26] A. J. Teichtahl, A. E. Wluka, Y. Wang et al., "Occupational activity is associated with knee cartilage morphology in females," Maturitas, vol. 66, no. 1, pp. 72-76, 2010.

[27] G. Xu, The investigation of MSDs of coal miners, [M.S. Thesis], Shantou University (in Chinese), Shantou (China), 2011.

[28] J. Sun, J. Zhang, W. Li, and S. Wang, "Investigation and analysis of musculoskeletal disorders and influencing factors in gas station workers," Industrial Health and Occupational Diseases, vol. 36, no. 2, pp. 105-106, 2010.

[29] P. Yan, F. Li, L. Zhang et al., "Prevalence of work-related musculoskeletal disorders in the nurses working in hospitals of 
Xinjiang Uygur Autonomous Region,” Pain Research \& Management, vol. 2017, article 5757108, 7 pages, 2017.

[30] H. Nassif, N. Brosset, M. Guillaume et al., "Evaluation of a randomized controlled trial in the management of chronic lower back pain in a French automotive industry: an observational study," Archives of Physical Medicine and Rehabilitation, vol. 92, no. 12, pp. 1927-1936.e4, 2011.

[31] H. Ge, X. Sun, J. Liu, and C. Zhang, "The status of musculoskeletal disorders and its influence on the working ability of oil workers in Xinjiang, China," International Journal of Environmental Research and Public Health, vol. 15, no. 5, p. 842, 2018.

[32] V. Volberg, T. Fordyce, M. Leonhard, G. Mezei, X. Vergara, and L. Krishen, "Injuries among electric power industry workers, 1995-2013," Journal of Safety Research, vol. 60, pp. 9-16, 2017.

[33] M. Blagojevic, C. Jinks, A. Jeffery, and K. P. Jordan, "Risk factors for onset of osteoarthritis of the knee in older adults: a systematic review and meta-analysis," Osteoarthritis and Cartilage, vol. 18, no. 1, pp. 24-33, 2010.

[34] D. A. Rice, M. T. Kluger, P. J. McNair et al., "Persistent postoperative pain after total knee arthroplasty: a prospective cohort study of potential risk factors," British Journal of Anaesthesia, vol. 121, no. 4, pp. 804-812, 2018.

[35] G. Cai, M. Jiang, F. Cicuttini, and G. Jones, "Association of age, sex and BMI with the rate of change in tibial cartilage volume: a 10.7-year longitudinal cohort study," Arthritis Research \& Therapy, vol. 21, no. 1, p. 273, 2019.

[36] Y. Zhang, M. ElGhaziri, S. Nasuti, and J. F. Duffy, "The comorbidity of musculoskeletal disorders and depression: associations with working conditions among hospital nurses," Workplace Health \& Safety, vol. 68, no. 7, pp. 346-354, 2020.

[37] J. Heikkinen, R. Honkanen, L. Williams et al., "Depressive disorders, anxiety disorders and subjective mental health in common musculoskeletal diseases: a review," Maturitas, vol. 127, pp. 18-25, 2019.

[38] K. W. Kim, S. G. Lee, and G. S. Hwang, "The mental health and occupational characteristic of horse stable hand workers in Korea," Safety and Health at Work, vol. 10, no. 3, pp. 384388, 2019.

[39] M. Heidari, M. G. Borujeni, P. Rezaei, and S. Kabirian Abyaneh, "Work-related musculoskeletal disorders and their associated factors in nurses: a cross-sectional study in Iran," Malaysian Journal of Medical Sciences, vol. 26, no. 2, pp. 122-130, 2019.

[40] M. Feuerstein, W. S. Shaw, R. A. Nicholas, and G. D. Huang, "From confounders to suspected risk factors: psychosocial factors and work-related upper extremity disorders," Journal of Electromyography and Kinesiology, vol. 14, no. 1, pp. 171178, 2004.

[41] C. L. Dennis, "Peer support within a health care context: a concept analysis," International Journal of Nursing Studies, vol. 40, no. 3, pp. 321-332, 2003. 